\title{
Health spending expenditures for commercial plans are predominantly concentrated among a small population of high-intensity consumers across settings of care
}

Michael Ciarametaro, MBA; Michael Kleinrock, MA; Allen Campbell; Lisabeth Buelt, MPH; and Robert W Dubois, MD, PhD

\section{What is already known about this subject}

- As US health care expenditures continue to rise, there is growing policy momentum aimed at managing health care spending.

- Numerous studies have found that annual US health care expenditures are predominantly concentrated among a small population of highintensity consumers of health care resources.

\section{What this study adds}

- This study explores how health spending is distributed across consumers and how utilization and spending patterns compare across health care resource expenditures (eg, hospital services, prescription drugs, or outpatient care)

- Our analysis of a large commercially insured population found that spending was concentrated within a small population of high-intensity consumers across all examined segments of care, including prescription drugs, inpatient care, and ambulatory care.

- Spending patterns across segments of care indicate that curbing rising health care spending will require systemwide evaluation of the value of health spending within and across settings of care for a subset of high-resource-use patients.

\author{
Author affiliations \\ Michael Ciarametaro, MBA; Lisabeth \\ Buelt, MPH; and Robert W. Dubois, MD, \\ PhD, National Pharmaceutical Council, \\ Washington, DC. Michael Kleinrock, MA, and \\ Allen Campbell, IQVIA Institute for Human \\ Data Science, Plymouth Meeting, PA. \\ AUTHOR CORRESPONDENCE: \\ Michael Ciarametaro, 202.827.2082; \\ mciarametaro@npcnow.org
}

J Manag Care Spec Pharm. 2022;28(2):180-87

Copyright $(2022$, Academy of Managed Care Pharmacy. All rights reserved.

persist when looking at individual segments of spending, including spending on prescription drugs and inpatient and ambulatory services. Inpatient spending was the most concentrated, with $97 \%$ of spending occurring within the top tenth percentile of patients.

CONCLUSIONS: Our findings suggest that health care spending for commercial plans is predominantly concentrated within a small population of high-intensity consumers across all settings of care. Curbing rising health care spending will require systemwide 
evaluation of the value of spending within and across settings of care for a subset of high-resource-use patients. This is particularly important for health care settings with the highest concentration of spending, including inpatient care.

For decades, average annual growth in health spending has outpaced average annual growth in the US gross domestic product (GDP), causing overall health spending to assume an increasingly growing share of the US GDP, rising from 5\% of GDP in 1960 to $17.7 \%$ in 2019. ${ }^{1}$ At the same time, numerous studies have shown that annual US health care expenditures are predominantly concentrated within a small group of high-intensity health care consumers. ${ }^{2,3}$ For example, in 2017, the United States spent $17.9 \%$ of GDP on health care ${ }^{4}$ but the top 5\% of health care consumers accounted for over $50 \%$ of overall health care expenditures. ${ }^{5}$

As annual health care expenditures continue to rise, curbing health care spending has become a key policy priority, as rising health care spending has significant implications for state and federal budgets. Recently, health care decision makers have identified several potential drivers of rising health care expenditures, including hospital consolidation, a high prevalence of chronic disease, and higher prices. ${ }^{6-8}$

However, little is known about how health care spending is distributed across consumers or how utilization patterns compare across health care resource expenditures (eg, hospital, outpatient care). Given that the majority of annual national health expenditures are concentrated in a small percentage of the population, it is important to examine and compare spending across the health care

\begin{tabular}{|c|c|c|c|c|}
\hline TABLE 1 & \multicolumn{2}{|c|}{ Summary of Patient Spend for the 2018 Plan Year } \\
$\begin{array}{l}\text { Percentile of } \\
\text { population }\end{array}$ & $\begin{array}{c}\text { Number of } \\
\text { patients }\end{array}$ & $\begin{array}{c}\text { Commercial } \\
\text { total spend }\end{array}$ & $\begin{array}{c}\text { Commercial total } \\
\text { spend adjusted for } \\
\text { rebates }\end{array}$ & $\begin{array}{c}\text { Percentage of } \\
\text { total spend }\end{array}$ \\
\hline p 1 & 179,354 & $27,324,670,196$ & $26,457,471,658$ & 27.6 \\
\hline p 5 & 925,896 & $54,950,367,995$ & $53,019,437,553$ & 55.3 \\
\hline 10 & $1,863,066$ & $68,916,537,106$ & $66,555,019,042$ & 69.4 \\
\hline 15 20 & $2,794,714$ & $76,913,222,638$ & $74,282,416,326$ & 77.5 \\
\hline p 25 & $3,721,310$ & $82,215,714,584$ & $79,404,414,168$ & 82.8 \\
\hline 50 & $4,645,790$ & $86,043,777,298$ & $83,110,231,856$ & 86.7 \\
\hline 0 & $9,214,631$ & $95,512,418,173$ & $92,307,054,045$ & 96.0 \\
\hline
\end{tabular}

Note: We applied a $15 \%$ rebate to pharmacy spend based on a Pew Charitable Trusts analysis of retail pharmaceutical spending, rebates, and coupons across payer types for the 2016 plan year. ${ }^{9}$ This rebate was applied uniformly across percentiles.

system to identify areas of irregular or high-magnitude spend. Findings from such analyses can provide important context when developing public policies aimed at managing rising health care spending. Therefore, this analysis examined commercial health care spending across 5 settings of care (ambulatory services, inpatient services, office visits, pharmacy services, and additional services) to identify utilization and spending patterns across multiple sectors of the US health care system.

\section{Methods}

We conducted a retrospective claims analysis for the 2018 plan year (January 2018-December 2018) using the IQVIA PharMetrics Plus database, which contains adjudicated commercial health insurance claims. The PharMetrics Plus database predominantly includes enrollees of employer-sponsored health plans but also includes a small number of individuals covered by Medicare Advantage, supplemental Medicare, and Medicaid. The database is representative of the commercially insured population under the age of 65 years in the United States, reflecting approximately $18 \%$ of commercially covered lives across census regions. Additionally, the PharMetrics Plus database includes robust cost, utilization, and enrollment information; is linkable to other real-world data assets; and allows for visibility across all settings of care. However, the database only contains health plan data and only captures health care experiences paid for by the plan. Therefore, items that are not covered by the plan do not appear in the data (eg, low-cost generics paid for by cash, cosmetic surgery).

This analysis included 16,872,732 patients who were continuously enrolled for the 2018 plan year. Spending and utilization were assessed across 5 settings of care: ambulatory services (outpatient hospitals, ambulatory surgical centers, and urgent care centers), inpatient services (inpatient hospitals, psychiatric facilities, and rehabilitation facilities), office visits (physician office or clinic and either individual or group practice), pharmacy services (retail, mail, and specialty pharmacies), and additional services (includes all other types of service not categorized elsewhere 


\begin{tabular}{|c|c|c|c|}
\hline \multirow{2}{*}{$\begin{array}{c}\text { TABLE } 2 \\
\text { Health } \\
\text { spending } \\
\text { segment } \\
\end{array}$} & \multicolumn{3}{|c|}{ Total Spending by Category of Spending } \\
\hline & $\begin{array}{c}\text { Percentage of } \\
\text { total spend for } \\
\text { the } 2018 \text { plan } \\
\text { year }\end{array}$ & $\begin{array}{l}\text { Percentage of } \\
\text { total spend } \\
\text { when adjusted } \\
\text { for rebates }\end{array}$ & $\begin{array}{c}\text { Gini } \\
\text { coefficient }\end{array}$ \\
\hline Druga $^{a}$ & 28.5 & 26.1 & 0.80883 \\
\hline Ambulatory ${ }^{b}$ & 26.4 & 27.3 & 0.826038 \\
\hline Inpatient ${ }^{c}$ & 19.1 & 19.7 & 0.973767 \\
\hline Office $^{d}$ & 18.4 & 19.1 & 0.49038 \\
\hline $\begin{array}{l}\text { Additional } \\
\text { servicese }^{\mathrm{e}}\end{array}$ & 7.5 & 7.8 & 0.832787 \\
\hline \multicolumn{4}{|c|}{$\begin{array}{l}\text { aClaims from pharmacy services (retail, mail, and specialty pharmacies) and } \\
\text { the sum of prescription drug spending from the ambulatory, office, pharmacy, } \\
\text { and additional services settings of care. Due to database limitations, this } \\
\text { segment excludes prescription drugs administered during inpatient stays but } \\
\text { does include drugs administered in outpatient settings. } \\
\text { bService claims from outpatient hospitals, ambulatory surgical centers, and } \\
\text { urgent care centers. } \\
\text { 'Claims from inpatient hospitals, psychiatric facilities, and rehab facilities. } \\
\text { 'Claims from physician offices or clinics, either individual or group practice. } \\
\text { eIncludes all other types of service not categorized elsewhere such as } \\
\text { laboratory, home health, nursing facilities, and emergency department. }\end{array}$} \\
\hline
\end{tabular}

such as laboratory, home health, nursing facilities, and emergency department).

Because spending on prescription drugs occurs in multiple settings of care, we defined "drug spending" as the sum of prescription drug spending from the ambulatory, office, pharmacy, and additional services settings of care. Due to database limitations, our calculation of drug spending excludes prescription drugs administered during inpatient stays but does include drugs administered in outpatient settings. Claims were categorized into 5 spending segments: inpatient, drug spend, ambulatory, office, and additional services.

Spending concentration was analyzed by calculating the Gini coefficient and examining population percentiles. To form percentile groups, all patients in the sample were rank-ordered from highest to lowest by their 2018 expenditures and assigned a percentile group based on their rank-order position.

To explore how health care resources are distributed across and within settings of care and spending segments, we evaluated the following commercial spending metrics: (1) overall spending concentration for all patients in the 2018 plan year as measured by Gini coefficient and percentile distribution; (2) overall spending concentration by spending segment as measured by Gini coefficient and percentile distribution; (3) total spending per patient by spending segment; (4) average total spending per patient by setting of care and percentile range; and (5) utilization in each spending segment (as measured by patient count).

To ensure the analysis reflected realistic marketplace conditions, we conducted sensitivity analyses by applying rebates to pharmacy spend. Where indicated, we applied a $15 \%$ rebate to pharmacy spend based on a Pew Charitable Trusts analysis of retail pharmaceutical spending, rebates, and coupons across payer types for the 2016 plan year. ${ }^{9}$ This rebate was applied uniformly across percentiles.

\section{Results}

First, we examined the overall spending patterns for all patients who were continuously enrolled in a health plan in the 2018 plan year (Table 1). We found that the top 1\% of patients accounted for nearly $28 \%$ of spending, while the top $5 \%$ accounted for more than $55 \%$ of spending. We then examined how overall spending was allocated among segments of care and conducted a sensitivity analysis adjusting drug spend for rebates to reflect current market conditions (Table 2).

Drug spending was the largest contributor to overall health care spending in our sampled population of commercially insured enrollees. Of the total health care expenditures $(\$ 99,144,803,318), 28.5 \%(\$ 28,283,041,800)$ of spending was attributed to prescription drug spending across all settings of care, followed by ambulatory spending (26.4\%) and inpatient spending (19.1\%). However, when drug spending was adjusted for rebates, prescription drug spending shrank to $26.1 \%$ and ambulatory spending became the largest share of spending (27.3\%).

Second, we calculated the Gini coefficient for total spending and by spending segment (Table 2). A 0 Gini coefficient indicates spending is equally distributed across commercial plan members, while a 1 coefficient indicates that spending is concentrated in a very narrow set of plan members. We calculated a 0.757656 Gini coefficient for total spending, indicating significant spending concentration. Ambulatory, drug, and additional spending coefficient values were similar to total spending, with values ranging between 0.80883 and 0.832787 . Inpatient spending was significantly more concentrated, with a 0.973767 coefficient. In contrast, office spending was significantly more dispersed, with a coefficient at 0.49038 .

Third, we explored overall spending by population percentile and spending segment (Figure 1). We found that the inpatient and office visit spending categories deviated most from the mean spending curve. For example, inpatient spending was the most concentrated of all segments, with nearly $50 \%$ of inpatient spend occurring in the top $1 \%$ of spenders, $85 \%$ occurring within the top $5 \%$, and $97 \%$ 


\section{FIGURE 1 Percentage of Total Spend by Segment and Percentile}

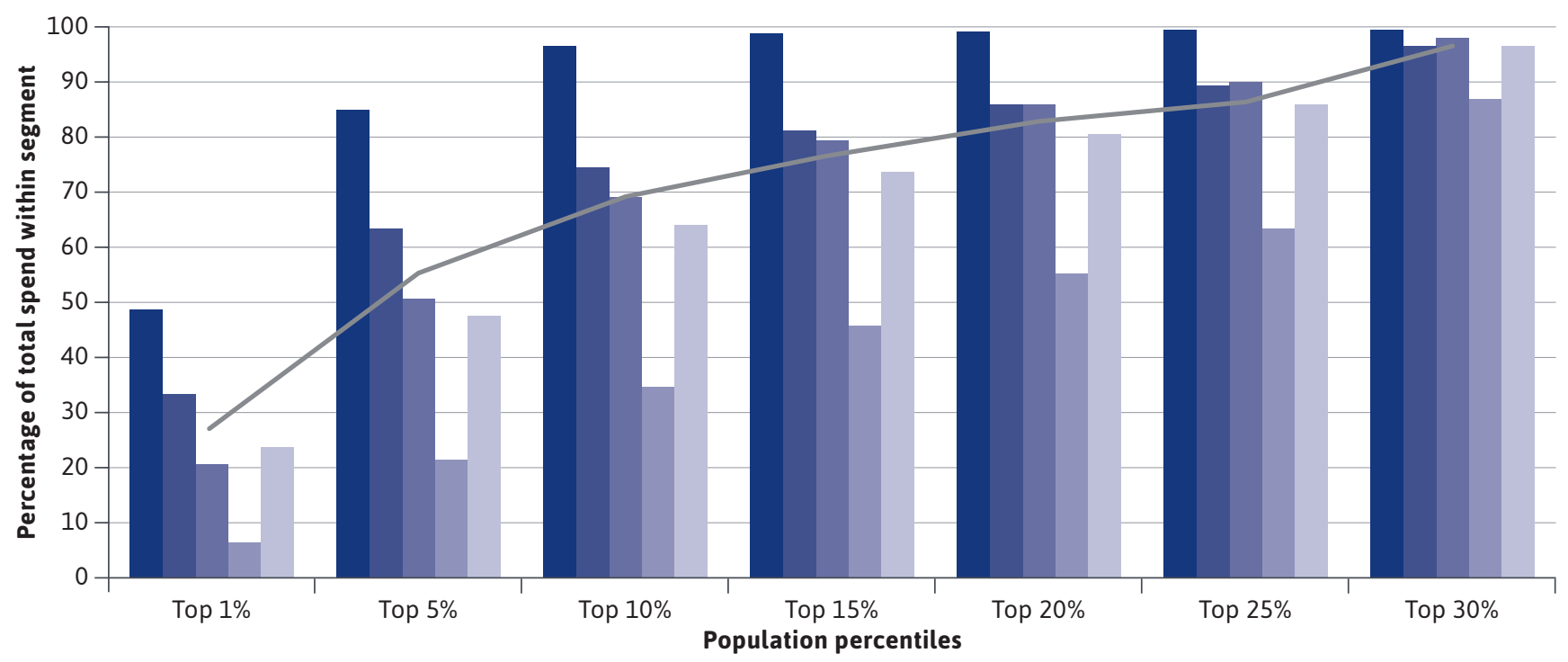

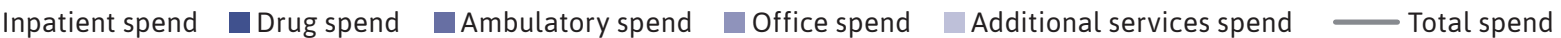

occurring in the top 10\%. Drug spending was the second most concentrated, with $33.5 \%$ of total spending occurring in the top $1 \%$ of spenders and $63.7 \%$ occurring in the top $5 \%$ of spenders. Ambulatory and additional services spending followed a similar pattern, with $50.8 \%$ and $47.9 \%$ of total spending occurring in the top $5 \%$ of spenders, respectively. Office spending was the least concentrated, with the biggest change in spending occurring between the 25.01 and 50 percentiles $(63.4 \%-87.8 \%)$.

Fourth, we examined average spending per patient by setting of care (Figure 2). Overall, the average total spending per patient across all segments of care among patients in the top $1 \%$ of spending was $\$ 152,350$. Conversely, average spending per patient in the bottom 50\% was $\$ 474$. Total average spending per patient dropped $80 \%$ between the top $1 \%$ and $1.01 \%$ to $5 \%$ range (\$152,350-\$29,837), indicating that the preponderance of spending occurs among the top $1 \%$ of patients.

When examining the 5 health spending segments, we found that average spending was highest in the inpatient spending category on a per-patient basis for the top 15\% of spenders. Per-patient spending was second highest in the drug spending category among the top $1 \%$ of health care spenders (\$52,831 per patient) but closer to other spending segments as the population percentiles increased. Ambulatory spending per patient was second highest (slightly higher than drug spend) for the $1.01 \%$ to $5 \%$ range (\$11,509 per patient) but followed the mean thereafter. However, ambulatory spending per patient exceeded drug spend per patient in the $1.01 \%$ to $25 \%$ range when prescription drug rebates were considered.

Fifth, we examined the number of unique patients accessing each setting of care to get a better sense of how utilization varied among spending percentiles and across spending segments (Table 3). There were 179,354 unique patients in the top 1 percentile. Over $99 \%$ of patients had at least 1 prescription drug claim $(n=179,120), 98 \%$ had at least 1 office visit $(n=176,344)$, and $61 \%$ had at least 1 inpatient claim $(n=108,833)$. Utilization diverged across spending segments as population percentiles increased. Utilization patterns remained similar (ie, highest for prescription drugs and office visits), for which utilization by unique patients was $94 \%$ and $97 \%$, respectively, even in the $25.01-$ 50 percentile. 


\section{FIGURE 2 Average Total Spend per Person by Setting of Care and Range}

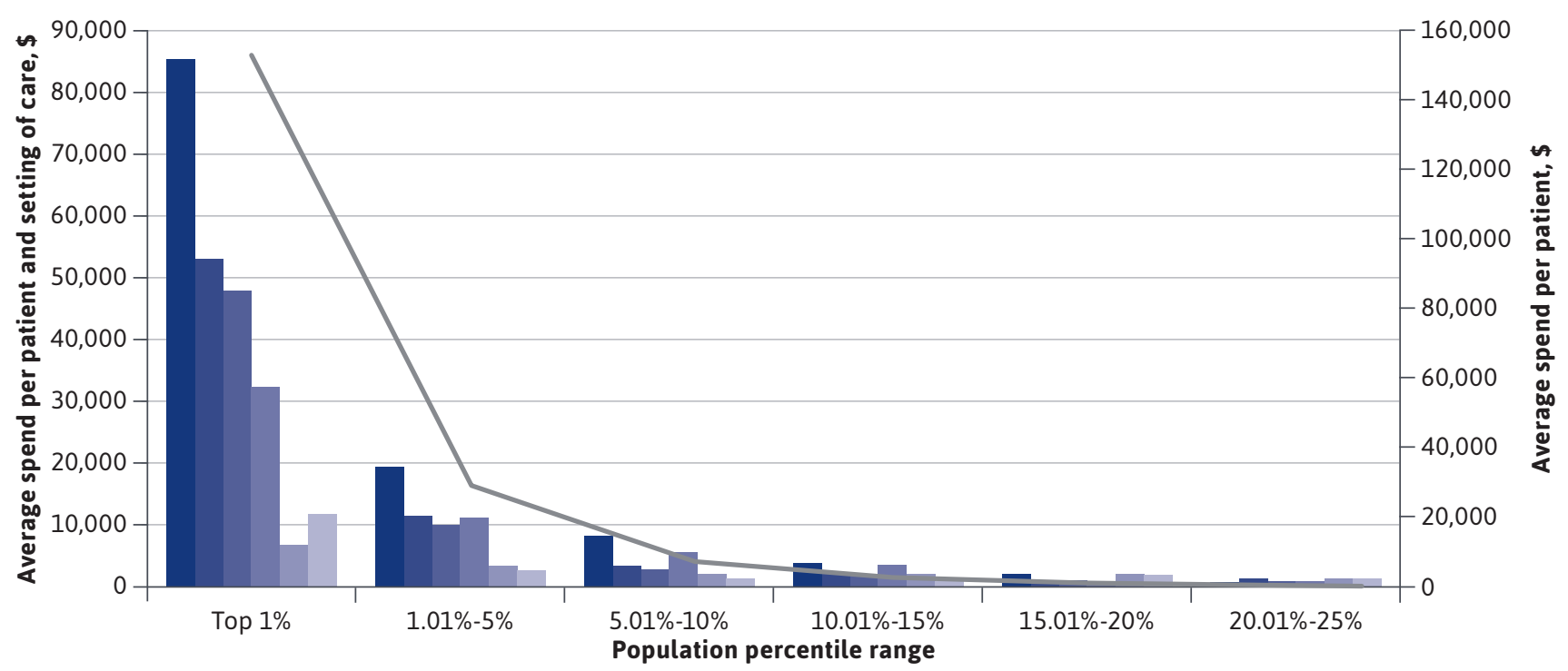

\section{Discussion}

We evaluated health care expenditures in a commercial population to compare utilization and spending patterns across segments and settings of care. We found that the top $5 \%$ of sampled individuals ranked by their total health care expenditures were responsible for $55.3 \%$ of total spending. These findings are consistent with previous analyses that have found substantial spending concentration among a small percentage of the overall patient population (ie, "frequent fliers"), ${ }^{2,4,5}$ Previous analyses have found that high-resource-use patients are typically older individuals who suffer from multiple chronic physical and mental health conditions ${ }^{2,11}$; however, additional research is needed to improve understanding of this population and the contextual factors driving their health care utilization.

When examining spending by health care segment, we found that spending concentration, as measured by Gini coefficient and percentile distribution, was generally consistent across the ambulatory, drug, and additional spending segments across all examined metrics. Spending on office visits was less concentrated than all other areas of spend. Inpatient spending, which involves the most intensive setting of care, had the highest per-patient expenditures in the top population percentiles, and spending was significantly more concentrated as measured by the Gini coefficient. Drug spending was the second largest driver of spending in the top percentiles; however, drug spending was less concentrated than inpatient spending $33.5 \%$ vs $49.2 \%$, respectively, in the top 1 percentile). Additional research is needed to further determine the characteristics of high-resource-use patients. Further exploration of this population may foster better care delivery and more efficacious health care interventions (eg, more accurate diagnoses, medications, and treatments will help lead to advanced identification and more suitable treatment).

Spending per patient declined significantly across all spending segments as the population percentiles increased. Per-patient inpatient spending exceeded prescription drug spending in the top $50 \%$ of patients when spending was adjusted for rebates. Drug and ambulatory care utilization 


\section{TABLE 3 Utilization and Spend per Population Percentile, by Spending Segment}

\begin{tabular}{|c|c|c|c|c|c|c|c|c|c|c|c|c|c|c|}
\hline \multirow[b]{3}{*}{$\begin{array}{l}\text { Spending } \\
\text { segment }\end{array}$} & \multicolumn{14}{|c|}{ Utilization by population percentile } \\
\hline & \multicolumn{2}{|c|}{ Top $1 \%$} & \multicolumn{2}{|c|}{ Top $1.01 \%-5 \%$} & \multicolumn{2}{|c|}{ Top 5.01\%-10\% } & \multicolumn{2}{|c|}{ Top $10.01 \%-15 \%$} & \multicolumn{2}{|c|}{ Top $15.01 \%-20 \%$} & \multicolumn{2}{|c|}{ Top $20.01 \%-25 \%$} & \multicolumn{2}{|c|}{ Top $25.01 \%-50 \%$} \\
\hline & $\begin{array}{l}\text { Unique } \\
\text { patients }\end{array}$ & $\%$ & $\begin{array}{l}\text { Unique } \\
\text { patients }\end{array}$ & $\%$ & $\begin{array}{l}\text { Unique } \\
\text { patients }\end{array}$ & $\%$ & $\begin{array}{l}\text { Unique } \\
\text { patients }\end{array}$ & $\%$ & $\begin{array}{l}\text { Unique } \\
\text { patients }\end{array}$ & $\%$ & $\begin{array}{l}\text { Unique } \\
\text { patients }\end{array}$ & $\%$ & $\begin{array}{l}\text { Unique } \\
\text { patients }\end{array}$ & $\%$ \\
\hline Inpatient & 108,833 & 60.70 & 346,563 & 46.40 & 269,381 & 28.70 & 103,314 & 11.10 & 39,568 & 4.30 & 21,321 & 2.30 & 39,854 & 0.90 \\
\hline Drugs & 179,120 & 99.90 & 744,971 & 99.80 & 931,543 & 99.40 & 918,502 & 98.60 & 904,640 & 97.60 & 893,488 & 96.60 & $4,284,105$ & 93.80 \\
\hline Ambulatory & 169,723 & 94.60 & 673,279 & 90.20 & 819,062 & 87.40 & 781,921 & 83.90 & 728,301 & 78.60 & 680,307 & 73.60 & $2,666,820$ & 58.40 \\
\hline Office & 176,344 & 98.30 & 734,898 & 98.40 & 921,036 & 98.30 & 912,839 & 98.00 & 904,369 & 97.60 & 899,749 & 97.30 & $4,413,475$ & 96.60 \\
\hline $\begin{array}{l}\text { Additional } \\
\text { services }\end{array}$ & 149,329 & 83.30 & 585,360 & 78.40 & 689,824 & 73.60 & 615,906 & 66.10 & 565,622 & 61.00 & 531,577 & 57.50 & $2,183,890$ & 47.80 \\
\hline $\begin{array}{l}\text { Total unique } \\
\text { patients }\end{array}$ & \multicolumn{2}{|c|}{179,354} & \multicolumn{2}{|c|}{746,542} & \multicolumn{2}{|c|}{937,170} & \multicolumn{2}{|c|}{931,648} & \multicolumn{2}{|c|}{926,596} & \multicolumn{2}{|c|}{924,480} & \multicolumn{2}{|c|}{$4,568,841$} \\
\hline $\begin{array}{l}\text { Spending } \\
\text { segment }\end{array}$ & \multicolumn{14}{|c|}{ Spend per segment, by population percentile } \\
\hline Inpatient & \multicolumn{2}{|c|}{$9,313,032,054.26$} & \multicolumn{2}{|c|}{$6,840,766,517.24$} & \multicolumn{2}{|c|}{$2,219,057,840.48$} & \multicolumn{2}{|c|}{$423,531,260.12$} & \multicolumn{2}{|c|}{$77,129,418.25$} & \multicolumn{2}{|c|}{$25,065,451.97$} & \multicolumn{2}{|c|}{$26,368,074.36$} \\
\hline Drugs & \multicolumn{2}{|c|}{$9,463,079,523.98$} & \multicolumn{2}{|c|}{$8,554,404,048.66$} & \multicolumn{2}{|c|}{$3,178,968,114.47$} & \multicolumn{2}{|c|}{$1,955,534,172.17$} & \multicolumn{2}{|c|}{$1,312,432,191.59$} & \multicolumn{2}{|c|}{$905,962,101.18$} & \multicolumn{2}{|c|}{$2,146,773,892.08$} \\
\hline Ambulatory & $5,541,162$ & 334.75 & $7,749,095$ & 783.76 & 4,880,240, & 647.73 & 2,794,313, & 407.70 & $1,674,766$, & 824.66 & $1,084,127,0$ & 088.39 & $2,014,913$ & 933.08 \\
\hline Office & $1,221,279$ & 582.83 & $2,684,351$ & 251.95 & $2,457,795$ & 491.64 & $2,071,737$ & 381.26 & $1,717,224$ & 179.42 & $1,435,311$, & 966.82 & $4,456,713$, & ,977.29 \\
\hline $\begin{array}{l}\text { Additional } \\
\text { services }\end{array}$ & $1,786,116$ & 700.42 & $1,797,080$, & 196.83 & 1,230,107, & 016.67 & 751,569 & 310.93 & 520,939 & 331.93 & 377,596, & 105.81 & 823,870 & - 998.65 \\
\hline $\begin{array}{l}\text { Total } \\
\text { spend per } \\
\text { population } \\
\text { percentile }\end{array}$ & $27,324,6$ & 70,196 & $27,625,6$ & 97,798 & $13,966,1$ & 69,110 & $7,996,6$ & 85,532 & $5,302,4$ & 91,945 & $3,828,0$ & 62,714 & $9,468,6$ & 40,875 \\
\hline $\begin{array}{l}\text { Spending } \\
\text { segment }\end{array}$ & & & & & Average & er pat & penaing & , оу po & tation pe & centile & & & & \\
\hline Inpatient & 85 & 571.77 & 19,7 & 738.88 & & 237.62 & & 099.46 & & 949.29 & & 175.62 & & 661.62 \\
\hline Drugs & & 830.95 & 11, & 482.87 & & 412.58 & & 129.05 & & 450.78 & & 013.96 & & 501.10 \\
\hline Ambulatory & 32, & 648.27 & 11 & 509.49 & & 958.33 & & 573.65 & & 299.55 & & 593.59 & & 755.55 \\
\hline Office & & 925.55 & & 652.69 & & 668.51 & & 269.55 & & 898.81 & & 595.24 & & 009.80 \\
\hline $\begin{array}{l}\text { Additional } \\
\text { services }\end{array}$ & & 960.95 & & 070.04 & & 783.22 & & 220.27 & & 921.00 & & 710.33 & & 377.25 \\
\hline
\end{tabular}

Note: Spending included in this table for the prescription drug spending segment is not adjusted for rebates.

were widespread across commercial membership based on unique patient utilization numbers. However, ambulatory spending was the biggest overall cost contributor when prescription drug rebates were considered.

Utilization varied substantially by spending segment and population percentile. Utilization in the top 1 percentile ranged from $99.9 \%$ in the prescription drug spending segment to $60.7 \%$ in the inpatient spending segment, but utilization diverged as population percentiles increased. While the inpatient setting had the highest per-patient spending, very few patients above the 15 th percentile had an inpatient claim. This indicates that a smaller group of patients are contributing to higher inpatient spend relative to other settings of care.

Our findings have 2 main policy implications. First, spending by segment and setting of care for a commercial plan population is consistent with a health system in which the sickest patients will consume the greatest number of resources. As a result, policies that aim to arbitrarily reduce high spending concentration via utilization incentives (eg, health plans with high cost-sharing) or health care price restrictions (eg, caps on specialty drug prices) lack 
requisite nuance and may unintentionally limit patient access to needed, high-value treatments without appropriate understanding, intervention, and resolution of patients' health care needs. Rather, health care payers and policies should focus on appropriate use of care and examine frequent flier patients more closely for proactive identification and optimized care.

Second, a significant portion of health care spending is concentrated in a small population. Therefore, managing rising health spending requires that health care decision makers evaluate the value of care delivered to this subset of patients.

\section{LIMITATIONS}

Our analysis has 3 main limitations. First, this analysis examines 1 year of utilization and spending in a commercially insured population and cannot speak to how the concentration of spending has changed over time. Given the significant concentration of patient spending in the top $10 \%$ of spenders, long-term trends are unlikely to change our conclusion that drug spending is consistent with overall spending. Moreover, our analysis is consistent with several cross-sectional analyses of health spending concentration published by the Agency for Healthcare Research and Quality. ${ }^{2,10}$

Second, our calculations that adjusted for prescription drug rebates relied on a Pew Charitable Trusts' estimate that we applied uniformly. Rebates are more common in drug classes with higher spending and competition, and the distribution of rebates across overall prescription drug spending is unknown. However, we used a conservative commercial rebate estimate of $15 \%$, which implies that the impact of this is minimal.

Third, this analysis exclusively examines spending within the commercially insured population and predominantly includes enrollees of employer-sponsored health plans under the age of 65 , a population that has lower inpatient stays compared with the general population, including Medicare and Medicaid. ${ }^{12,13}$ As a result, our analysis of the commercial market finds a higher proportion of drug spending of total spending than is present in the general population. ${ }^{14}$

\section{Conclusions}

Commercial health plan spending is largely concentrated within a small population of high-intensity consumers of health care. This pattern persists when examining spending in individual health care segments, including inpatient services, ambulatory services, and prescription drugs. Inpatient spending was revealed to be the most concentrated of all evaluated spending segments. Curbing rising health care spending will require systemwide evaluation of the value of spending within and across settings of care for a subset of high-resource-use patients.

\section{DISCLOSURES}

This study was funded by the National Pharmaceutical Council (NPC). Ciarametaro, Buelt, and Dubois are employed by the NPC. Kleinrock and Campbell are employed by IQVIA, which was contracted by the NPC for data analysis.

\section{REFERENCES}

1. Centers for Medicare \& Medicaid Services. Historical national health expenditure data. Table 01 national health expenditures; aggregate and per capita amounts. Accessed October 5, 2021. https://www.cms.gov/ResearchStatistics-Data-and-Systems/ Statistics-Trends-and-Reports/ NationalHealthExpendData/ NationalHealthAccountsHistorical
2. Mitchel EM. Concentration of health expenditures and selected characteristics of high spenders, U.S. civilian noninstitutionalized population, 2016. Agency for Healthcare Research and Quality. Statistical Brief \#521. February 2019. Accessed October 5, 2021. https://meps. ahrq.gov/data files/publications/st521/ stat521.shtml

3. Cohen SB. The concentration and persistence in the level of health expenditures over time: estimates for the U.S. population, 2012-2013. September 2015. Accessed October 5, 2021. https://meps. ahrq.gov/data files/publications/st481/ stat481.pdf

4. Keehan SP, Cuckler GA, Poisal JA, Sisko AM, Smith SD, Maidson AJ, et al. National health expenditure projections, 2019-28: expected rebound in prices drives rising spending growth. Health Aff (Millwood). 2020;39(4):704-14.

5. Mitchell EM. Concentration of healthcare expenditures and selected characteristics of high spenders, U.S. civilian noninstitutionalized population, 2017. Statistical brief \#528. February 2020. Accessed October 6, 2021. https:// meps.ahrq.gov/data files/publications/ st528/stat528.shtml

6. 166th Congress. Elijah E. Cummings Lower Drug Costs Now Act, HR 3. 166th Cong. 2020. Accessed October 6, 2021. https://www.congress.gov/ bill/116th-congress/house-bill/3

7. Berenson RA, King JS, Gudiksen KL, et al. Addressing health care market consolidation and high prices. January 2020. Accessed October 6, 2021. https://www.urban.org/sites/ default/files/publication/101508/ addressing_health_care_market_consolidation and high prices 1.pdf

8. Thorpe KE, Ciarametaro M, Dubois RW. It is not just the prices! The role of chronic disease in accounting for higher health care spending in the United States. J Chronic Dis Manag. 2021;(5)1:1025. 
9. Pew Charitable Trusts. The prescription drug landscape, explored. March 2019. Accessed October 6, 2021. https://www. pewtrusts.org/-/media/assets/2019/03/ the_prescription_drug_landscapeexplored.pdf

10. Mitchell E. Concentration of health expenditures in the U.S. noninstitutionalized population, 2014. Statistical brief \#497. November 2016. Accessed October 6, 2021. http://www.meps.ahrq.gov/ mepsweb/data_files/publications/st497/ stat497.pdf

11. Krie C, Hudon C, Chouinard MC, Dufour I. Individual predictors of frequent emergency department use: a scoping review. BMC Health Serv Res. 2016;16(1)594.
12. America's Health Insurance Plans. Where does your health care dollar go? November 12, 2020. Accessed October 6, 2021. https://www.ahip.org/ health-care-dollar/

13. Sun R, Karaca Z, Wong H. Trends in hospital inpatient stays by age and payer, 2000-2015. January 2018. Accessed October 6, 2021. https://www.hcup-us. ahrq.gov/reports/statbriefs/sb235-Inpatient-Stays-Age-Payer-Trends.jsp
14. Cubanski J, Rae M, Damico A. How does prescription drug spending and use compare across large employer plans, Medicare Part D, and Medicaid? May 20, 2019. Accessed October 6, 2021. https://www.healthsystemtracker.org/ chart-collection/how-does-prescriptiondrug-spending-and-use-compare-acrosslarge-employer-plans-medicare-part-dand-medicaid/\#item-start 